\title{
Cardiac and extra-cardiac pathologies in patients with acute arterial occlusion
}

\author{
Mehmet Ali Kaygin' \\ (iD) Umit Halici ${ }^{2}$ \\ (D) Mehmet Tort ${ }^{3}$ \\ (iD) Ziya Yildiz ${ }^{3}$ \\ (iD) Ozgur Dag 1
}

1. Cardiovascular Surgery Department, Erzurum Regional Training and Research Hospital, University of Health Sciences, Erzurum, Turkey 2. Cardiovascular Surgery Department, Samsun Training and Research Hospital, Samsun, Turkey 3. Cardiovascular Surgery Department, Erzurum Regional Training and Research Hospital, Erzurum, Turkey

http://dx.doi.org/10.1590/1806-9282.65.11.1368

\section{SUMMARY}

OBJECTIVE: We aimed to investigate cardiac and extra-cardiac pathologies in patients who were operated for acute arterial occlusion. METHODS: Between March 2010 and March 2018, a total of 120 patients who underwent surgical treatment for acute arterial occlusion were included in this retrospective study.

RESULTS: 84 (70\%) and 27 (22. 5\%) of the patients had cardiac and extra-cardiac pathologies, respectively. In 9 (7. 5\%) of the cases, no reason for arterial occlusion could be found. Pure atrial fibrillation was found in 39 (32. 5\%) patients. Atrial fibrillation and cardiac valvular pathologies were detected in 45 patients (37.5\%). Among those with a cardiac valvular pathology, 9 patients (7.5\%) had pure mitral stenosis, 21 patients (17. 5\%) had moderate to advanced mitral stenosis with tricuspid regurgitation, 9 patients $(7.5 \%)$ had $2^{\circ}-3^{\circ}$ mitral regurgitation with $3^{\circ}$ tricuspid regurgitation, 3 patients $(2.5 \%)$ had moderate mitral stenosis, $3^{\circ}-4^{\circ}$ tricuspid regurgitation and $2^{0}-3^{\circ}$ aortic stenosis, and 3 patients $(2.5 \%)$ had $3^{\circ}$ mitral regurgitation, $1^{0}-2^{0}$ tricuspid regurgitation, calcific moderate aortic stenosis, and coronary artery disease. Among those 27 patients with an extra-cardiac pathology, 21 patients (22. 5\%) had peripheral artery disease, 3 patients (2.5\%) had an abdominal aortic aneurysm, and 3 patients (2. 5\%) had Behçet's Disease.

CONCLUSION: Cardiac and extra-cardiac pathologies should be kept in mind in patients with acute arterial occlusion. Thus, detected pathologies could be treated, and the development of additional peripheral emboli could be prevented.

KEYWORDS: Arterial Occlusive Diseases. Embolectomy. Thromboembolism.

\section{INTRODUCTION}

Acute arterial occlusion can occur in any peripheral artery of the extremities and can lead to limb ischemia. Also, prolonged ischemia cause increased morbidity and mortality in patients with acute arterial occlusion'. It was known that acute arterial occlusion is generally the result of thrombus. The term 'embolus' originates from the Greek word 'embolos', which means stopper or plug'. In patients with acute peripheral arterial obstruc- tion, early embolectomy operation is recommended without preoperative invasive examination to prevent distal thrombus migration and recurrent thrombus formation ${ }^{3}$. It was known that acute arterial occlusion could be of cardiac or extra-cardiac (atheroembolic or thrombotic) origin. We aimed to investigate cardiac and extra-cardiac pathologies in patients who were operated for acute arterial occlusion. 


\section{METHODS}

Between March 2010 and March 2018, A total of 120 patients (63 females [52. 5\%], 57 males [47. 5\%], aged 24-79 years, mean age of $45 \pm 8.5$ years] who underwent surgical treatment for acute arterial occlusion were included. Records of these patients were analyzed. Informed consents of the patients were obtained before the operation. Approval of the local ethics committee was obtained. The main complaints were coldness and pain in their toes, feet, fingers, and arms. The diagnosis was made through physical examination, Doppler ultrasonography (USG), and infrequently through peripheral computed tomography (CT) angiography. The time between the onset of pain at the affected extremity and admission at the hospital was between 2 hours to 5 days [mean duration $19 \pm 6$ hours]. Unilateral and bilateral femoral embolectomies were performed to the femoral artery in $87(72.5 \%)$ and 24 (20\%) of the patients, respectively. Also, unilateral brachial artery embolectomy was performed in 9 (7. 5\%) patients. Echocardiography and electrocardiography that had been performed for cardiac pathologies and cardiac rhythm problems in all patients were evaluated. Additional investigation modalities were performed in patients who were suspected of having different pathologies.

\section{RESULTS}

A total of $84(70 \%)$ and $27(22.5 \%)$ patients had cardiac and extra-cardiac pathologies, respectively. In $9(7.5 \%)$ of the cases, no reason for arterial occlusion could be found, as shown in Figure 1. Pure atrial fibrillation was found in 39 (32. 5\%) patients as a cardiac pathology. Atrial fibrillation and cardiac valvular pathologies were detected in 45 patients (37. 5\%). Among those with a cardiac valvular pathology, 9 patients (7. 5\%) had pure mitral stenosis, 21 (17.5\%) had moderate to advanced mitral stenosis with tricuspid regurgitation, $9(7.5 \%)$ had $2^{\circ}-3^{\circ}$ mitral regurgitation with $3^{\circ}$ tricuspid regurgitation, $3(2.5 \%)$ had moderate mitral stenosis, $3^{\circ}-4^{\circ}$ tricuspid regurgitation and $2^{\circ}-3^{\circ}$ aortic stenosis, and 3 patients (2. 5\%) had $3^{\circ}$ mitral regurgitation, $1^{\circ}-2^{\circ}$ tricuspid regurgitation, calcific moderate aortic stenosis and coronary artery disease (Table 1). Among those 27 patients with an extra-cardiac pathology; 21 (22. 5\%) had peripheral artery disease (atherosclerosis), 3 (2. 5\%) had abdominal aortic aneurysm, and $3(2.5 \%)$ had Behçet's Disease.

A total of thirty- five patients (32.1\%) had additional surgical operations, of which 8 (6. 6\%), 9 (7. $5 \%), 12(10 \%)$ and 6 (5\%) had re-embolectomy, peripheral arterial bypass operation, fasciotomy, and amputation, respectively. Re-embolectomy operation was successful in 2 patients, but ischemia was not recovered in 6 of the patients who had had dropfeet, ischemic, and infected wounds when they arrived at the hospital. In these patients, fasciotomy was performed for compartment syndrome caused by ischemia-reperfusion damage after the re-embolectomy operation, and after that, amputation was performed (below-knee amputations). On the other hand, extremities in other $6(5 \%)$ patients with fasciotomy operation were saved with medical treatment, and fasciotomies were closed later.
FIGURE 1. ETIOLOGIES DETECTED IN PATIENT

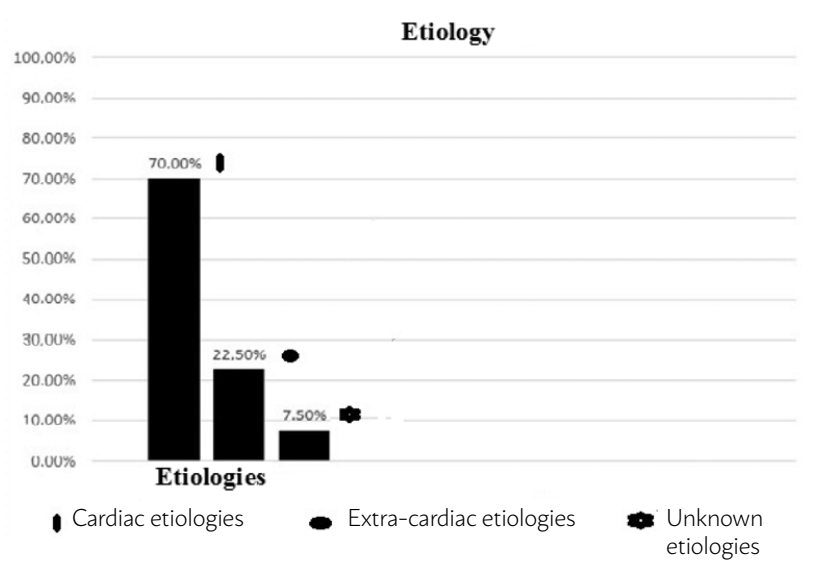

TABLE 1. DISTRIBUTION OF EMBOLIES ACCORDING TO ETIOLOGY

\begin{tabular}{l|l|l} 
Etiology & $\begin{array}{l}\text { number } \\
(\mathbf{n})\end{array}$ & $\begin{array}{l}\text { percentage } \\
(\%)\end{array}$ \\
\hline Cardiac causes & 84 & 70 \\
\hline Pure atrial fibrillation & 39 & 32.5 \\
\hline Atrial fibrillation + pure mitral stenosis & 9 & 7.5 \\
\hline $\begin{array}{l}\text { Atrial fibrillation + multiple valvular } \\
\text { pathologies }\end{array}$ & 33 & 27.5 \\
\hline $\begin{array}{l}\text { Atrial fibrillation + multiple valvular } \\
\text { pathologies + coronary artery disease }\end{array}$ & 3 & 2.5 \\
\hline Extra-cardiac pathology & 27 & 22.5 \\
\hline Peripheral artery disease & 21 & 17.5 \\
\hline Abdominal aortic aneurysm & 3 & 2.5 \\
\hline Behçet's disease & 3 & 2.5 \\
\hline Unknown etiology & 9 & 7.5 \\
\hline
\end{tabular}


TABLE 2. COMPLICATIONS OF PERIPHERAL ARTERIAL EMBOLECTOMY OPERATION

\begin{tabular}{l|l|l} 
Complication & number $(\mathrm{n})$ & percentage (\%) \\
\hline Wound Infection & 3 & 2.5 \\
\hline Compartment syndrome & 12 & 10 \\
\hline Amputation & 6 & 5 \\
\hline Hematoma/ecchymosis & 9 & 7.5 \\
\hline Bleeding & 3 & 2.5 \\
\hline Cerebral embolism & 3 & 2.5 \\
\hline
\end{tabular}

Peripheral CT angiography was performed in patients who had ongoing extremity ischemia after embolectomy operation, and patients indicated for peripheral artery bypass operation were detected. After that, femoropopliteal artery by-pass with $6 \mathrm{~mm}$ polytetrafluoroethylene (PTFE) synthetic graft and cross-femoral artery by-pass with $7 \mathrm{~mm}$ PTFE synthetic graft were performed in $6(5 \%)$ and $3(2.5 \%)$ patients, respectively. After these operations, patients' extremities were recovered, and there was no need for any additional attempts.

Wound infection, hematoma, bleeding from the incision, amputation, compartment syndrome and cerebral embolism developed in $3(2.5 \%), 9(7.5 \%)$, $3(2.5 \%), 6(5 \%), 12(10 \%)$, and $3(2.5 \%)$ patients, respectively, in the early postoperative period. These complications are presented in Table 2 .

All patients received $175 \mathrm{IU} / \mathrm{kg} /$ day low-molecular-weight heparin for three days in the early postoperative period. Warfarin was started later in patients with atrial fibrillation, whereas antiplatelet therapy with $\mathrm{N}$-acetyl salicylic acid $300 \mathrm{mg} /$ day and/or clopidogrel $75 \mathrm{mg}$ /day were given to other patients. Warfarin doses were adjusted for an international normalized ratio (INR) of 2 - 3. Following coumadinization, the low-molecular-weight heparin treatment was discontinued. During the follow-up period, the patients' vital signs were stable, so they were discharged. The patients were called at the outpatient clinic one week after discharge. Peripheral artery bypass grafts and extremity artery lumens at the thrombectomy sites were patent, and their treatment was continued. There was no in-hospital mortality.

\section{DISCUSSION}

Prevalence of acute arterial occlusion is between $7-37.5 \%$ among all vascular diseases ${ }^{3}$. In previous years, arterial embolism was most com- monly seen between the ages of 40 and $50^{4}$. Currently, the average patient age has shifted to the 70s, as the etiologic factor, atherosclerotic heart disease and its complications are frequently found to be responsible for $i^{4}$. Embolism was first described by Virchow in $1854^{1}$. The thrombotic material in acute arterial occlusion due to arterial embolism detaches from a distant site and occludes a normal blood vessel. Embolectomy operation has been performed for a long time, and the first successful embolectomy operation was performed by Labey in $1911^{4}$. The balloon catheter was developed by Fogarty in $1963^{5}$. Then it started to be used in embolectomy operations of patients with arterial thromboembolism. In physical examination, the 6 Ps that are diagnostically important are pain, paleness, paresthesia, pulselessness, paralysis, prostration (shock), and poikilothermia'. The differential diagnosis is very important in acute arterial occlusion. Advanced diagnostic methods such as Doppler USG, intravascular USG, and magnetic resonance (MR) can be used ${ }^{3}$. On the other hand, Bahçıvan et al. ${ }^{6}$ have reported reaching a diagnosis with clinical findings and hand Doppler USG in most patients in their study, without using any radiological examinations with an intention not to cause an increase in the duration of acute ischemia. We accurately diagnosed our patients by using hand Doppler USG, Doppler USG, peripheral CT angiography after a physical examination, especially pulse examination.

In cases with acute arterial occlusion, an increase in the duration from the onset of complaints to admission to the hospital has a negative effect on the success of arterial embolectomy operation. It was known that this duration should not exceed 6-8 hours. Likewise, Mutirangura et al. ${ }^{7}$ have reported that the 24- hour duration of arterial embolism may be a crucial factor influencing the outcome in the management of this disease. Moreover, Pung and Mohamed $^{8}$ have detected that the cause for poor results were related to the delay in definitive treatment and the poor general state of the patients. In our patients, the time between the onset of pain in the extremity and admission to the hospital was between 2 hours and 5 days [mean duration $19 \pm 6$ hours], and patients underwent emergency embolectomy after the diagnosis without any delay. However, this time in patients who underwent fasciotomy was between 48 - 120 hours (mean duration $72 \pm 12$ hours).

Cardiac origin is detected in most of the cases of 
peripheral arterial embolism ${ }^{9,10}$, which is the most frequent cause of acute arterial occlusion. Ege et al. ${ }^{1}$ have reported this rate as $80-90 \%$ in their study, and have remarked that arterial embolus was observed secondary to heart diseases such as rheumatic valvular heart disease, atrial fibrillation, and myocardial infarction. Other cardiac causes include post-valve replacement, cardiac/aortic tumor, and paradoxical embolism $^{10}$. However, atrial fibrillation accounts for most of the sources of the cardiac embolism in patients with peripheral arterial embolism ${ }^{10}$. On the other hand, Keçeligil et al. ${ }^{4}$ have found a cardiac origin and an extra-cardiac origin in $62.56 \%$ and 30. $72 \%$ of the cases, respectively, and could not find any origin in $6.7 \%$ of the patients. However, in the same study, the embolic origin was expressed as cardiac in $78 \%$ of cases with acute peripheral arterial occlusion, in all series ${ }^{4}$. Also, Yetkin et al. ${ }^{2}$ have reported that for the 51 patients who underwent urgent unilateral femoral embolectomy, it was determined that 28 (55\%) had serious cardiac pathologies. Among these 28 patients, 14 (50\%) underwent the required openheart surgery interventions after the completion of further examinations. In our study, cardiac pathology was detected in $70 \%$ of the patients compatible with the medical literature, and extra-cardiac pathologies were detected in $22.5 \%$ of the cases, and $7.5 \%$ had unknown etiology. However, over time, rheumatic heart disease-induced cardiac embolism is decreasing, but the incidence of acute arterial occlusion due to acute thrombosis that develops based on atherosclerotic vascular disease is increasing ${ }^{11}$.

Acute arterial thrombosis is an important cause of extremity loss, and embolectomy intervention does not provide sufficient circulation in some patients. For example, in this study, 8 (6. 6\%) and 9 (7. $5 \%)$ of patients have had re-embolectomy operation and peripheral arterial bypass operation, respectively due to ongoing ischemia and previous peripheral artery disease. Peripheral arterial bypass operation was performed after the effective visualization of vascular structure was shown by CT angiography.

The presentation of arterial emboli depends on the arterial bed that is affected. The two most common sites for embolic events are brain and lower extremities. On the other hand, less frequent sites are upper extremities ${ }^{12}$, mesenteric vessels, and the renal arteries ${ }^{12}$. Erkut et al. ${ }^{13}$ have reported timely arterial embolectomy under local anesthesia to be the most effective method of treatment in acute arterial occlusion.
Also, Erentuğ et al. ${ }^{3}$ have mentioned that standard treatment of acute peripheral arterial occlusion consists of heparinization and embolectomy, but thrombolytic therapy [such as urokinase, streptokinase, recombinant tissue plasminogen activator ( $r$-tPA)] in recent years is preferred, especially in patients with acute occlusion that develops on a chronic atherosclerotic basis. However, Vinayagam et al. ${ }^{14}$ have reported that peripheral thrombolysis is associated with a $10 \%$ risk of hemorrhage, which may require blood transfusion, operation, or cause death from bleeding. Also, intracranial hemorrhage (0 to $2.5 \%$ ), compartment syndrome (1 to $10 \%$ ), and distal embolization (1 to $5 \%$ ) could be seen as other complications of catheter-directed thrombolysis for acute arterial occlusion ${ }^{15}$. Moreover, Ourie ${ }^{16}$ have emphasized in his article that thrombolysis has been associated with hemorrhagic complications, a slow rate of thrombus dissolution, and a higher risk of rethrombosis. Whereas, in this study, heparin was administered, and emergency arterial embolectomy operation was performed as soon as possible in all patients with acute arterial occlusion after the diagnosis.

Various postoperative complications, such as wound infection, hematoma, bleeding from the incision, amputation, cerebral embolism, and compartment syndrome, could also be seen in the early postoperative period. Compartment syndrome is a clinical condition that is characterized by a functional loss of muscle and nerve tissues and develops as a result of ischemia, which can occur due to increased perfusion pressure within closed muscle fascia of the extremities ${ }^{17}$. Tissue reperfusion after ischemia can cause reperfusion syndrome ${ }^{17}$. Fasciotomy might be needed for decreasing the pressure on all tissues under the skin. Thus, adequate perfusion could be provided. Erentuğ et al. ${ }^{3}$ have reported the rate of fasciotomy in their study as $4.7 \%{ }^{3}$. Burma et al. ${ }^{18}$ have suggested that patients should be followed up after embolectomy operation and fasciotomy should be performed before the irreversible ischemia-reperfusion phase. As well, Tawes et al. ${ }^{19}$, reported that their 20-year experience with lower extremity thromboembolism in 739 patients was associated with a mortality rate of $12 \%$, a wound complication rate of $19 \%$, and a morbidity (amputation) rate of $5 \%$. Also, Dag et al. ${ }^{20}$ had focused on risk factors for amputation in 822 cases with acute arterial emboli in their study and reported that an interval of more than 6 hours between the onset of complaints and operation 
and re-embolectomies increase the risks of amputation. Kempe et al. ${ }^{21}$ reported that the 90-day major amputation rate was $15 \%$, and the 30 -day mortality rate was $18 \%$. Also, they reported in that study, the 5 -year estimated limb salvage was $80 \%$, and survival was $41 \%^{21}$. In this study, fasciotomy was performed in $12(10 \%)$ patients with acute lower extremity compartment syndrome in the early postoperative period. Then, below-knee amputation was performed in $6(5 \%)$ of them despite medical treatment.

It was known that arterial thromboembolism could be caused by various diseases. Investigation of all patients for additional pathologies was performed after the surgery. Definitive diagnosis was made, and then additional treatment was applied for etiology. For example, abdominal aortic aneurysm and Behçet's disease that were of extra-cardiac pathology were detected in a total of $6(5 \%)$ patients as a result of the investigation. During the treatment and follow up, cardiac and extra-cardiac pathologies that were detected were also treated. We could not find any etiology in $9(7.5 \%)$ patients.

This study has some limitations. First, it is a retrospective study, and it lacked mid-term and long term control findings of patients. Second, we had a small sample size. Third, the patients were discharged, and the treatments for additional cardiac and extracardiac pathologies were performed later. Therefore, detailed information about these treatments was not mentioned in this study.

\section{CONCLUSION}

In conclusion, cardiac and extra-cardiac pathologies should be kept in mind in patients with arterial thromboembolism, and a detailed cardiovascular examination is of utmost importance for the differential diagnosis and treatment plan. Thus, other serious pathologies detected could be treated as soon as possible, and the development of additional peripheral emboli could be prevented. Also, the arrangement for appropriate treatments may prolong the life span of these patients.

\section{Declaration of conflict of interest}

The authors declare no conflicts of interest concerning the authorship and/or publication of this article.

\section{Funding}

The authors received no financial support for the research and/or authorship of this article.

\section{Author's contribution}

MK - Conceptualization, Data curation, Validation, Investigation, Methodology, Project administration, Writing-original draft

UH - Formal analysis, Software, Supervision, Writing-review \& editing

MT - Data curation

ZY - ResourcesOD - Funding acquisition, Visualization

\section{RESUMO}

OBJETIVO: O objetivo do estudo é investigar patologias cardíacas e extracardíacas em pacientes operados por oclusão arterial aguda.

MÉTODOS: Entre março de 2010 e março de 2018, um total de 120 pacientes submetidos a tratamento cirúrgico para oclusão arterial aguda foram incluídos neste estudo retrospectivo.

RESULTADOS: Dos pacientes incluídos, 84 (70\%) e 27 (22.5\%) apresentavam, respectivamente, patologias cardíacas e extracardíacas. Em 9 (7.5\%) dos casos, nenhuma cause para a oclusão arterial foi encontrada. Fibrilação atrial isolada foi encontrada em 39 (32.5\%) pacientes. Fibrilação atrial e valvopatias cardíacas foram detectadas em 45 pacientes (37.5\%). Entre aqueles com valvopatias cardíacas, 9 (7.5\%) tinham estenose mitral isolada, 21 (17. 5\%) tinham estenose mitral moderada a avançada com regurgitação tricúspide, 9 (7. 5\%) tinham $2^{\circ}-3^{\circ}$ de regurgitação mitral com 30 regurgitação tricúspide, $3(2.5 \%)$ tinham estenose mitral moderada, $3^{\circ}-4^{\circ}$ regurgitação tricúspide e $2^{\circ}-3^{\circ}$ estenose aórtica, e 3 (2.5\%) tinham 30 mitral, $7^{\circ}$ - $2^{\circ}$ regurgitação tricúspide moderada, estenose aórtica moderada calcificada e doença coronariana. Entre os 27 pacientes com patologia extracardíaca, 21 (22.5\%) tinham doença arterial periférica, 3 (2,5\%) tinham aneurisma da aorta abdominal, e 3 (2.5\%) tinham Doença de Behçet.

CONCLUSÃO: Patologias cardíacas e extracardíacas devem ser consideradas em pacientes com oclusão arterial aguda. Assim, patologias detectadas podem ser tratadas e o desenvolvimento de trombos periféricos adicionais pode ser evitado.

PALAVRAS CHAVE: Arteriopatias Oclusivas. Embolectomia. Tromboembolia. 


\section{REFERENCES}

1. Ege T, Canbaz S, Sunar H, Çıkırıkçıoğlu M, Halıcı Ü, Duran E. Surgical treatment for acute arterial occlusion. Balkan Med J. 2002;19:89-95.

2. Yetkin U, Abud B, Gökalp O, Özpak B, Sahin A, Göktoğan T, et al. Investigation of the embolic foci through echocardiographic evaluation in patients undergoing urgent femoral embolectomy. Anadolu Kardiyol Derg. 2009;9(1):37-40

3. Erentuğ V, Mansuroğlu D, Bozbuğa NU, Erdoğan HB, Elevli MG, Bal E, et al. Surgical treatment of acute arterial occlusions. Turk Gogus Kalp Dama. 2003;11:236-9.

4. Keçeligil HT, Küsdül M, Gökgözoğlu G, Saraç A, Kolbakır F, Akar H, et al. Acute peripheral arterial occlusions: review of 179 cases. Turk Gogus Kalp Dama. 1999;7:319-23.

5. Fogarty TJ, Cranley JJ. Catheter technic for arterial embolectomy. Ann Surg. 1965;161:325-30.

6. Bahçıvan M, Saraç A, Demirağ MK, Doyurgan O, Kolbakır F, Keçeligil T. Thromboembolic occlusion of upper extremity arteries. Turk Gogus Kalp Dama. 2008;16:20-3.

7. Mutirangura P, Ruangsetakit C, Wongwanit C, Sermsathanasawadi N, Chinsakchai K. Acute arterial embolism of the lower extremities: impact of 24-hour duration on the outcome of management. J Med Assoc Thai. 2008;91(9):1360-7.

8. Pung LY, Mohamed SR. Peripheral arterial embolism: a prospective study of 40 consecutive cases. Med J Malaysia. 1990;45(2):131-5.

9. Pereira Barretto AC, Nobre MR, Mansur AJ, Scipioni A, Ramires JA. Peripheral arterial embolism. Report of hospitalized cases. Arq Bras Cardiol. 2000;74(4):324-8

10. Obara H, Matsubara K, Kitagawa Y. Acute limb ischemia. Ann Vasc Dis. 2018;11(4):443-8.
11. Ertürk M, Sarıosmanoğlu N, Hazan E, Dicle O, Açıkel Ü, Oto Ö. Peripheric arterial by-pass consecutive to thrombolytic therapy in the management of acute arterial obstruction. Turk Gogus Kalp Dama. 1998;6:41-4.

12. Lyaker MR, Tulman DB, Dimitrova GT, Pin RH, Papadimos TJ. Arterial embolism. Int J Crit IIIn Inj Sci. 2013;3(1):77-87.

13. Erkut B, Becit N, Ünlü $Y$, Çolak A, Ateş A, Ceviz M, et al. Analysis of risk factors for amputation and mortality in 504 cases with acute arterial emboli. Turk J Vasc Surg. 2007;16:5-12.

14. Vinayagam K, Arumugam S, Rao UV, Vidyashankar S. Acute nontraumatic upper limb ischemia: a protocol for management. Indian J Surg. 2005;67(5):257-9.

15. Morrison HL. Catheter-directed thrombolysis for acute limb ischemia. Semin Intervent Radiol. 2006;23(3):258-69.

16. Ouriel K. Comparison of surgical and thrombolytic treatment of peripheral arterial disease. Rev Cardiovasc Med. 2002;3(Suppl 2):S7-16.

17. Sayar U, Özer T, Mataracı I. Forearm compartment syndrome caused by reperfusion injury. Case Rep Vasc Med. 2014; 931410.

18. Burma O, Uysal A, Akar I, Yücedağ E, Rahman A. Factors affecting thromboembolectomy in acute peripheral arterial occlusions. Turk Gogus Kalp Dama. 2005;13(4):369-73.

19. Tawes RL Jr, Harris EJ, Brown WH, Shoor PM, Zimmerman JJ, Sydorak $\mathrm{GR}$, et al. Arterial thromboembolism. A 20-year perspective. Arch Surg. 1985;120(5):595-9.

20. Dag $O$, Kaygın MA, Erkut B. Analysis of risk factors for amputation in 822 cases with acute arterial emboli. Scientific World J. 2012;2012:673483.

21. Kempe K, Starr B, Stafford JM, Islam A, Mooney A, Lagergren E, et al. Results of surgical management of acute thromboembolic lower extremity ischemia. J Vasc Surg. 2014;60(3):702-7. 